the payment cap brings the NIH scientists closer in line with their colleagues at public universities.

A new Office of Education. The office, which opened in June 1990, offers programmes for postdoctoral researchers on the belief that such nurturing will entice them to stay. In the last year and a half, the number of accredited MD residencies NIH offers has doubled. The six new ones, in sub-specialties of internal medicine such as haematology and infectious diseases, have been the most popular and account for the majority of increased applications. With research institutions increasingly looking for subspecialties experience, the new residencies should make researchers more marketable both outside and inside NIH, says Michael Fordis, the office's director. In addition, post-doctoral candidates can be as much as five years past their degree (the limit had been three years) and can remain for as long as seven years instead of three. The changes give NIH greater flexibility in hiring those who are changing careers or returning to work.

- Smarter recruiting. Rather than advertising postdoctoral positions individually, the new education office now takes out fullpage advertisements listing dozens of positions throughout NIH and highlighting opportunities in specific areas that crisscross several institutes. It has also created an electronic database of NIH positions and prints instructions for accessing the database by modem in its advertisements. Such salesmanship has sharply increased the number of inquiries about postdoctoral positions and resulted in 946 applications for 67 positions - a 14:1 ratio that is one of the highest in NIH history.

Earlier tenure tracks. NIH officials are now making a point of identifying the young researchers most likely to be offered tenure within a year or two and giving them extra laboratory resources and responsibilities. As Fordis puts it: "Young people going into research need a sense that they're going to be good at it." So rather than waiting the usual three or four years to select tenuretrack candidates - by which time many young researchers at NIH are already looking elsewhere - "we want to show them early on that there's a commitment to their career".

Officials are banking on NIH's reputation for quality and the opportunity it offers for both basic and clinical research. Half the clinical research beds in the United States are at NIH, and collaboration across disciplines often requires only a walk down the hall instead of a trip cross-country.

$\mathrm{NIH}$ is also counting on the fact that times are tough and that its disadvantages are minor compared with such chronic outside worries as rejected grant applications and university cutbacks. Twenty-five years after the Vietnam draft, NIH once again looks like a safe refuge.

Christopher Anderson

\title{
NIH looks inward and outside for ways to help minorities
}

The dual nature of the National Institutes of Health as both funding agency and in-house laboratory is well-illustrated by its efforts to increase the number of scientists from minority groups. At the same time that $\mathrm{NIH}$ wants to give US institutions millions of dollars to encourage minority students to go into biomedical research, its intramural programme is struggling to improve a

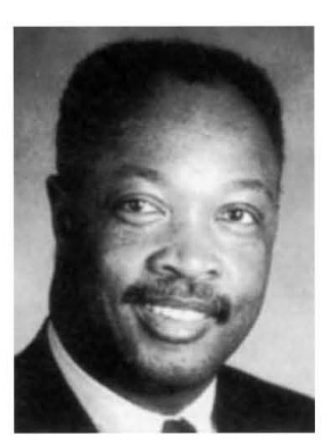

John Ruffin sorry record of hiring and promoting minority scientists on the Bethesda, Maryland, campus.

Congress seems favourably disposed to give NIH $\$ 20$ million in the fiscal year starting next month for new training programmes as part of a $\$ 45$-million initiative to improve the health of minorities. One aim is to attract minorities into graduate programmes by linking historically black colleges with major research universities. The students would simultaneously enrol in a master's programme at the black college and a doctoral programme at a nearby research university. Other initiatives would create a 'bridge' for students at twoyear community colleges to continue their education at four-year undergraduate universities and would support high school and middle school students in programmes intended to whet their appetites for more science as undergraduates.

At the same time, NIH would continue its support for two programmes begun in the 1970s, the Minority Access to Research Careers and Minority Biomedical Research Support, as well as a rapidly growing summer programme, a supplemental grants programme that adds minority scientists to existing research projects and in-service training for high school and undergraduate minority faculty. The new projects will be run from the two-year-old Office of Minority Affairs, headed by John Ruffin, which has asked for an additional \$9.8 million in 1993.

Although these programmes will help the overall research community, they will do little to improve the lot of the tiny number of minority scientists in the \$1-billion intramural research programme. NIH officials are reviewing a report submitted last month by outside consultants that paints a bleak picture of the chances of minorities becoming tenured scientists in the staff fellows programme, which is a primary way of attracting young talent to NIH. Although the odds in general are long - only about one in ten fellows win a permanent position at NIH by the end of their seven-year probationary period - the number of minority scientists who have done so can be counted on one hand.

The report, which took two years to complete, was carried out for NIH's Office of Equal Opportunity, which is responsible for seeing that all employees are treated fairly. Independently, the scientific directors of the intramural programmes at each NIH institute decided earlier this year to look at the issue of recruitment, retention and promotion of minority scientists and formed a committee led by Bruce Chabner of the National Cancer Institute. That committee is expected to use the consultants' findings in its own analysis, due by the end of the year.

One problem

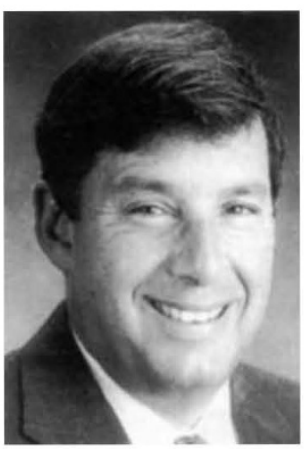

Bruce Chabner that institutions face is the stiff competition for the small number of qualified minority scientists, while students must overcome the high cost of earning an advanced degree, both in tuition fees and in a temporary loss of earnings. One so-

lution, says Chabner, is to support those who choose careers in research through tuition subsidies or by forgiving student loans.

But improving the lot of those who join NIH is equally important. Chabner estimates that there are no more than a dozen tenured minority scientists in the intramural programme, and some met each other for the first time as members of Chabner's committee, according to Michele Evans of the National Institute on Aging, who spent two and a half years as special assistant for minority affairs in the cancer institute.

There is no question that better answers are needed, says Bernadine Healy, director of NIH. Admitting that she was "disappointed" by what the consultants reported, Healy says that she has asked her staff to think about reasonable targets and "to become more aggressive" in recruiting, retaining and promoting minorities. "We have a problem", she says, "and the institute directors understand that this is one thing that they will be judged on" when their job performance is reviewed.

Jeffrey Mervis 